\title{
Is the TikTok Hype Real? A Contextual Analysis of the \#FordWatchMe Challenge
}

\author{
Markus Rach ${ }^{\mathrm{a}, 1}$ \\ ${ }^{a}$ University of Applied Sciences and Arts Northwestern Switzerland
}

\begin{abstract}
The objective of this research project was to spark academic discourse on the need for practitioner-oriented research in big data marketing applications. For this purpose, a specific TikTok Hashtag Challenge, \#FordWatchMe, was selected for its over 2.7 billion campaign impressions. Little to no scholarly research was identified to critically appraise the value of TikTok's user engagement and reported campaign metrics, despite TikTok's growing relevancy for marketers. A sequential mixed research method was designed, consisting of interviews, qualitative content reviews and a user engagement experiment to assess the relevancy of the \#FordWatchMe campaign for a defined sample. Analyzing over 450 campaign videos resulted in more than $88 \%$ campaign unrelated user generated content contributions. The user perception experiment revealed a low probability for both brand recall and content engagement. Findings showcase the need for more scholarly research on the value of superlative impression counts and their implied effect on brand recall, brand perception and purchase intent stimuli.
\end{abstract}

Keywords. TikTok, Social Media, Marketing, Advertising

\section{Introduction}

Since early 2020, TikTok established itself as the fastest growing, the most downloaded and the most hyped social media platform on the planet [1]. With over 3 billion downloads, TikTok has catapulted itself to become marketing and advertising mainstream, much supported by the platform's ever-growing business and advertising opportunities [2]. Many showcase campaigns on TikTok, such as the handwash challenge, run by Dettol in 2020, resulted in never heard of marketing reach. In Dettol's case, its paid TikTok Hashtag Challenge generated over 125 billion views [3]. A Hashtag Challenge is one of TikTok's premium advertising products, actively promoting the creation of user generated content, potentially using creative elements such as a campaign soundtrack, a branded effect and of course a challenge for users to creatively answer through their video content. Some other widely featured Hashtag Challenges include Chipotle's \#Boorito Hashtag Challenge, or Pringle's \#PlayWithPringles.

Despite TikTok's skewed demographic to the younger end [4], brands flock to the platform to capitalize on its still relative affordable reach [5]. Almost every industry, from sports, automotive to medicine, can be found on TikTok, with many engaging in the platform's paid advertising opportunities, or influencer campaigns [6], [7]. Likewise, scholars' interest in TikTok as a marketing and advertising platform has increased [8],

\footnotetext{
${ }^{1}$ Markus Rach, markus.rach@fhnw.ch, Institute of Competitiveness and Communication, University of Applied Sciences and Arts Northwestern Switzerland
} 
[9], [10]. However, very little research questioning the true effectiveness of TikTok, and its impressive reach potential was identified, despite the platform's very restricted access and information sharing information policy. As such, the app raises much ambiguity for marketers and scholars alike. For example, with 2.5 billion app downloads in 2020 [11], how could Dettol's TikTok campaign content have 125 billion views, or the equivalent of 33 views for each of 3.8 billion social media users in 2020 [12]. With less than 700 million reported monthly TikTok users during the campaign's lifetime [3], the above computes to a minimum of 179 views per active TikTok user. Assuming all views are true views, that is in TikTok terms any render of the video on a user's device, how many of these views are qualitative views? Qualitative in terms of target group reach, brand recall and brand favorability? How much of the user generated content, as part the user engagement of a campaign, is truly campaign relevant? These questions are of high relevancy for marketing budget allocations, with regards to optimizing the return on marketing investment. A non-representative survey on LinkedIn with 513 answers, the majority of which came from marketing professionals, revealed a high trust bias towards reported platform metrics. The latter formed the research aim of this paper.

To provide a use case and stimulate further discourse on these questions, the \#FordWatchMe Hashtag Challenge, by Ford Germany, has been selected for analysis. The selection was done based on current practitioners' media publications, which this campaign dominated. The campaign had at the time of analysis 2.7 billion views and formed part of a larger product launch by Ford Germany to introduce an all-electric vehicle to the German market. Starting in June, Ford Germany took it to TikTok to run a paid Hashtag Challenge, which got kickstarted with various sponsored influencer postings [13]. At the time of the content analysis, the $23^{\text {rd }}$ July 2021, 455 TikToks were uploaded using the campaign soundtrack, the hashtag \#forddeutschland displayed 8.2 million views and the campaign's underlying product, under the hashtag \#fordmustangmache, 29.2 million views. Ford Germany did not have an active TikTok account at the time of analysis. The commonality of all clips related to the Hashtag Challenge is the use of the hashtag \#FordWatchMe.

\section{Research}

This research project followed a mixed method research design [14] to instigate exploratory- and explanatory-research into the topic matter, while reducing the potential sequential method bias. Results are likely not representative but meant to stimulate further academic discourse to tighten the academic-practitioners' gap in performance relevant marketing matters. Particularly the wider field of data science is called upon to further investigate marketing decision making relevant metrics in the areas of unstructured data applications, such as short video, audio and other novel social media formats.

\subsection{Literature Review}

Academic research interest around TikTok amplified since 2017, which is evident through over $15 \mathrm{k}$ search findings for TikTok on Google Scholar and almost $5 \mathrm{~K}$ for TikTok and advertising. A similar search query on ScienceDirect displayed only 82 results. Most research on the topic relates to the impact TikTok holds on digital marketing [5], TikTok's use motivators [15], the impact of TikTok on users [16], 
predictors of success of product placement [17], the use of TikTok for politics [18], [19], medical content dissemination [20], its demographic makeup [21], or the TikTok algorithm [22]. No relevant research was identified to critically appraise the value of brands' TikTok engagement, other than optimization product conversion campaigns [17]. No research was identified to question the ambiguity of metrics, or generally unstructured format impacts. A deeper level of research was identified relating to TikTok's Chinese version Douyin [23], [24], which has however little generalization value in the west due to the higher content moderation practice, differing cultural spheres and of course more lenient privacy and data protection laws at work [25], [26]. For this reason, this research project seems highly relevant to stimulate the practitioner-oriented data science community for further research in this area.

A potential rational for the absence of academic research in the above areas is to be found in TikTok's young age. Academic research requires much time [27], which is evident by the ample of research available for other social media networks, such as Facebook [28].

\subsection{Creator Interviews}

Pre-dating the campaign analysis, a random selection of 10 campaign contributing TikTok creators were interviewed on their motivation to participate. Creators were randomly selected from the campaign's landing page and contacted through social media. Sponsored content creators were excluded from the preliminary interview round due to their obvious transactional relationship with the brand and campaign.

Out of all interviews, 8 out of 10 participants were unable to explain the Hashtag Challenge's objective. 6 out of 10 participants stated to have participated as a follow up to consumed user generated content. The main stimuli to participate was the campaign's soundtrack. 3 out 10 participants stated to have participated as a growth hacking attempt to boost views. None of the interview participants' motive of participation was related to either brand liking, brand affiliation, or brand engagement. Further, 4 out of 10 participants were in fact unaware of the Ford brand's sponsorship of the challenge.

It is important to note, that the campaign's creative did not receive further attention in this study. Creative introduces a high subjective bias, which further studies should consider as a moderating variable.

Preliminary interview findings support the need to further research this sample campaign's content relevancy to infer on the quality of generated views.

\subsection{Campaign Analysis}

Since TikTok does restrict automated third-party analysis of TikTok content and further restricts searchable results, the campaign analysis was conducted using video content found under the campaign soundtrack. Secondly, a random selection of campaign clips, from the Hashtag Challenge's landing page, was analyzed. In total, 301 clips using the campaign soundtrack ${ }^{2}$ and 150 random clips from the campaign landing page ${ }^{3}$ were selected. The 301 limit marked the maximum number of accessible clips for the campaign soundtrack. The analysis was conducted on pre-defined content criteria, by two independent researchers. Results were combined through an iterative process.

\footnotetext{
${ }^{2}$ https://vm.tiktok.com/ZMRD4NWYp/

${ }^{3}$ https://vm.tiktok.com/ZMRDXTfXW/
} 
Out of all clips using the campaign soundtrack, $48 \%$ used the branded effect, $2 \%$ were sponsored uploads, 5\% related to Ford, 10\% related to the Hashtag Challenge, 9\% had the campaign soundtrack muted or overlayed with other sound and $88 \%$ appeared non-campaign related. Out of the $10 \%$ uploads relating to the Hashtag Challenge, all but 2 applied the campaign's branded effect.

In all but 19 uploads, both researchers had matching relevancy ratings of uploads. Examples of the category of non-related campaign uploads include clips with a black screen, gaming recordings, advertising of a local fast-food shop, advertising for other businesses, the showcasing of random objects like lamps or bottles, people performing to the soundtrack, unrelated to the challenge, to trend watchers explaining why users should apply the campaign hashtag for a boost in views. The latter is congruent to some of the preliminary interview findings.

Out of the random sample not incorporating the campaign soundtrack, all 150 sampled videos were non campaign related. Some of the sample included dating tips, recordings of famous soccer players, lunchbox preparing instructions, comics and random tv recordings.

Since this sample analysis hints at a low user generated content relevancy to the analyzed campaign, a further user experiment was setup to assess brand recall and relevancy of user generated content to average TikTok users.

\subsection{User Experiment, Interviews and Marketing Manager Survey}

Following the quantitative campaign analysis, 20 TikTok users were recruited to qualitatively test the impact of branded effects on brand recall and overall perception. Since branded effects provide a visual stimulus, the purpose of these experiments was to assess, whether unrelated user generated content still provokes a positive brand effect. For this test, these 20 users were recruited on pre-defined criteria, such as geographic location, age, TikTok usage. Only users situated in Germany, being above the app's set minimum age of 13 and having an active TikTok account qualified for the experiment. User recruiting was done via an ad-supported network sampling technique on Facebook [29]. Participants were randomly split into two groups. Using videoconferencing systems, each participant was exposed to a total of 15 TikTok videos. 5 TikTok videos were randomly selected clips from the \#FordWatchMe campaign. Only clips using the campaign soundtrack were eligible. The other 10 clips were randomly selected TikToks using trending music. These 10 clips were shown to all 20 participants. The 5 \#FordWatchMe clips however differed for participants from group A vs. participants from group B. Group A was exposed to campaign clips using the campaign's branded effect, whilst group B was exposed to campaign clips not incorporating the branded effect. Participants were exposed only once to each clip. Following each viewing, participants were asked a standard set of questions about the clip's content, perception, favorability of the perceived content and their likely engagement. Participant interactions were recorded to reduce experiment and interview duration. All recordings were deleted post data analysis, compliant with privacy laws.

Both groups displayed a very similar attitude towards the overall likelihood of content engagement. Across the board this was non-existent for high engagement activities such as video shares, duets, or stitches. The latter are two popular TikTok reaction mechanisms. For low engagement tactics, group B displayed however a much 2 times higher likelihood to engage with the content through likes or comments than group A. Assessing brand recall and brand attitude differed much in weight between both 
groups. Group A displayed a 4 times higher brand recall, particularly after seeing the $2^{\text {nd }}$ or $3^{\text {rd }}$ campaign video, as compared to group B. For the latter, brand recall was below $10 \%$, due to the low perception of the Ford brand. Equally, the effect of hashtags on user brand recall behavior proved in this sample experiment very low for both groups. Group A however exhibited a higher sensitivity to the campaign hashtag \#FordWatchMe, which participants related to the branded effect group A was exposed to.

Further, a non-representative survey was conducted on LinkedIn with 266 participating B2C marketing managers in Germany. Only $17 \%$ questioned a nonqualitative impression metric as sufficient to determine the potential of a platform's paid media options for their brand. The vast majority viewed a high impression number as sufficient to assume a broad reach, justifying potential media investments.

\section{Results Discussion}

This research project analyzed an accessible sample of the \#FordWatchMe campaign on TikTok to estimate ambiguities of marketing practitioners when referring to impression metrics on TikTok for budget allocation decision making.

Whilst the selected campaign has 2.7 billion views, the analyzed sample revealed over $88 \%$ of campaign unrelated user generated content. The sample represented $66 \%$ of all uploads using the campaign's soundtrack. Campaign relevancy even decreased for a randomly generated, non-representative, sample of 150 clips not using the campaign soundtrack. Whilst the analyzed sample does not infer views, it poises to question the quality of views achieved. A follow up experiment suggested that most sampled users did not actively perceive the sponsoring brand. Visual clues in the form of branded effects provided a noticeable uplift in brand recall, compared to clips not having visual clues.

As existing studies confirmed [30], recall of video advertising is dependent on goaloriented consumption, which is to a higher degree impacted by product displays, compared to brand displays. This asks for a congruent goal-oriented purpose of branded content.

In summary, the findings of this research project raise various questions. First, on the qualitative side, what is the value of superlative impression metrics on the TikTok platform? How much do impression metrics dilute marketing budget decision making processes in favor of the TikTok platform? Although the views relating to this campaign could not be automatically processed, $88 \%$ campaign unrelated user generated content suggests a high ratio of non-qualitative impressions. Nevertheless, the conducted LinkedIn survey findings suggest a high positive bias towards impression metrics.

Second, what are the opportunity costs for marketers initiating non-product related user engagement campaigns with regards to brand recall and quality user engagement. How can these opportunity costs be qualified with regards to marketing return on investment? This study suggested a low brand recall for non-visually supported clips. Thus, marketing managers are advised to increase the use of visual stimuli in paid formats to maximize brand recall effects.

Thirdly, from an operational level, can brands impact the advertising intensity on both product and brand by stimulating a higher level of campaign related user generated content? How, if at all, is the latter perceived by marketing managers sighting competitive campaigns? 


\section{Conclusion}

This research project highlighted two separate issues demanding further research. First, academics and practitioners need to question the ambiguity and quality of impression metrics, particularly on platforms with restricted third-party access. With over $88 \%$ of campaign unrelated uploads identified in this project, brand perception and thus potential brand favorability impacts on scale need to be questioned. Particularly practitioners need to demand an impression and engagement quality score to better judge their relevant campaign reach.

Second, in the experiment conducted, visual aids such as the branded effect displayed the highest impact on brand recognition and thus brand recall. It is therefore advisable for practitioners to include visual brand clues in their creations. Due to the current trend to consume much video content without sound [31], visual recall aids are prone to receive an even higher importance in the coming future. The best placement of brand mentions has already been researched on TikTok, however the placement of visual clues to enhance brand recall and favorability demands further scholarly attention.

Finally, this research project evidenced the academic-practitioners' gap [32]. Whilst a lot of research has already been conducted on TikTok, very little focuses on current marketing practitioners' problems.

\section{Limitations And Further Research}

The following limitations have been noted. First, TikTok's restriction to search and data access did not allow for automated data queries or large-scale analysis of user generated content. Sampling data through a manual analysis of user generated content served as a mitigation measure yet exposing this research project to sampling and self-selection bias.

This research project hopes to spark further interest in the wider research and practitioners' community to expand upon these findings. Besides the quantitative validation of findings, auxiliary research is highly suggested, such as research on predicting factors of impression metrics' quality. It is argued that with the increasing focus on short video and other high impression formats, the stressed thematic becomes even more relevant for marketers.

\section{References}

[1] Rach M. The Influence of Brands and Platform Mechanics on Creator'Content Sovereignty on TikTok. InDigital Marketing \& eCommerce Conference 2021 Jun 29 (pp. 35-42). Springer, Cham.

[2] Ye J. TikTok tops 3 billion downloads worldwide, the first non-Facebook app to do so. South China Morning Post. 2021 Jul 15. Retrieved from https://www.scmp.com/tech/big-tech/article/3141181/tiktoktops-3-billion-downloads-worldwide-first-non-facebook-app-do

[3] Rach M. \#okBoomer: My TikTok experiment and what marketers should know about the platform!. 2020 March. Amazon Self-Publishing.

[4] Kennedy M. 'If the rise of the TikTok dance and e-girl aesthetic has taught us anything, it's that teenage girls rule the internet right now': TikTok celebrity, girls and the Coronavirus crisis. European Journal of Cultural Studies. 2020 Dec;23(6):1069-76.

[5] Guarda T, Victor JA, Augusto MF, Mazón LM, Lopes IM, Oliveira P. The impact of tiktok on digital marketing. ICMarkTech 2020. 2021;205:35-44.

[6] Haenlein M, Anadol E, Farnsworth T, Hugo H, Hunichen J, Welte D. Navigating the New Era of Influencer Marketing: How to be Successful on Instagram, TikTok, \& Co. California Management Review. 2020 Nov;63(1):5-25. 
[7] Su Y, Baker BJ, Doyle JP, Yan M. Fan engagement in 15 seconds: Athletes' relationship marketing during a pandemic via TikTok. International Journal of Sport Communication. 2020 Aug 27;13(3):43646.

[8] Ma R, Kim S. Use, Motivations, and Responses of TikTok as an Advertising Channel. The Journal of the Korea Contents Association. 2021;21(2):507-19.

[9] $\mathrm{Hu}$ Y. Research on the commercial value of Tiktok in China. Academic Journal of Business \& Management. 2020 Nov 6;2(7).

[10] Ma R, Kim S. Use, Motivations, and Responses of TikTok as an Advertising Channel. The Journal of the Korea Contents Association. 2021;21(2):507-19.

[11] Amore S. TikTok Tops 2.5 Billion in Global Downloads. THEWRAP. 2020 Nov 10. Retrieved from https://www.thewrap.com/tiktok-tops-2-5-billion-in-global-downloads/

[12] Hysa B, Karasek A, Zdonek I. Social media usage by different generations as a tool for sustainable tourism marketing in society 5.0 idea. Sustainability. 2021 Jan;13(3):1018.

[13] Bayer C. \#FordWatchMe - Ford verlängert Launchkampagne für den Mustang Mach-E mit einer TikTokChallenge. MEEDIA. 2021 Jun 06. Retrieved from https://meedia.de/2021/06/10/fordwatchme-fordverlaengert-launchkampagne-fuer-den-mustang-mach-e-mit-einer-tiktok-challenge/

[14] Creswell JW. Mixed-method research: Introduction and application. InHandbook of educational policy 1999 Jan 1 (pp. 455-472). Academic Press.

[15] Montag C, Yang H, Elhai JD. On the Psychology of TikTok Use: A First Glimpse From Empirical Findings. Frontiers in Public Health. 2021 Mar 16;9:62.

[16] Zhaoying G. The Influence of Short Video Platform on Audience Use and Reflections - Take TikTok as an example. Academic Journal of Humanities \& Social Sciences. 2021 May 12;4(4).

[17] Yang J, Zhang J, Zhang Y. INFLUENCER VIDEO ADVERTISING IN TIKTOK. MIT INITIATIVE ON THE DIGITAL ECONOMY. 202. Vol. 4

[18] Gonzalez A, Vandenbosch L. Politics Undercover: Understanding the Role of Social Media and Entertainment Series in Adolescents' Political Socialization. InInternational Political Psychology (IPoPsy) working group, Location: Online 2021.

[19] Medina Serrano JC, Papakyriakopoulos O, Hegelich S. Dancing to the partisan beat: a first analysis of political communication on TikTok. In12th ACM conference on web science 2020 Jul 6 (pp. 257-266).

[20] Zheng DX, Ning AY, Levoska MA, Xiang L, Wong C, Scott JF. Acne and social media: A cross-sectional study of content quality on TikTok. Pediatric Dermatology. 2021 Jan;38(1):336-8.

[21] Kennedy M. 'If the rise of the TikTok dance and e-girl aesthetic has taught us anything, it's that teenage girls rule the internet right now': TikTok celebrity, girls and the Coronavirus crisis. European Journal of Cultural Studies. 2020 Dec;23(6):1069-76.

[22] Klug D, Qin Y, Evans M, Kaufman G. Trick and Please. A Mixed-Method Study On User Assumptions About the TikTok Algorithm. In13th ACM Web Science Conference 20212021 Jun 21 (pp. 84-92).

[23] Meng KS, Leung L. Factors influencing TikTok engagement behaviors in China: An examination of gratifications sought, narcissism, and the Big Five personality traits. Telecommunications Policy. 2021 Aug 1;45(7):102172.

[24] Scherr S, Wang K. Explaining the success of social media with gratification niches: Motivations behind daytime, nighttime, and active use of TikTok in China. Computers in Human Behavior. 2021 Jun 3:106893.

[25] Kaye DB, Chen X, Zeng J. The co-evolution of two Chinese mobile short video apps: Parallel platformization of Douyin and TikTok. Mobile Media \& Communication. 2021 May;9(2):229-53.

[26] Sun L, Zhang H, Zhang S, Luo J. Content-based analysis of the cultural differences between TikTok and Douyin. In2020 IEEE International Conference on Big Data (Big Data) 2020 Dec 10 (pp. 4779-4786). IEEE.

[27] Zhang J, Huang X, Hao J, Crittenden JC. A guide to shortening the time from submission to publication in Frontiers of environmental science \& engineering. Frontiers of Environmental Science \& Engineering. 2020 Mar 9;14(2):35.

[28] Bhattacharyya S, Bose I. S-commerce: Influence of Facebook likes on purchases and recommendations on a linked e-commerce site. Decision Support Systems. 2020 Nov 1;138:113383.

[29] Baltar F, Brunet I. Social research 2.0: virtual snowball sampling method using Facebook. Internet research. 2012 Jan 27.

[30] Zhang X, Yuan SM. An eye tracking analysis for video advertising: Relationship between advertisement elements and effectiveness. IEEE access. 2018 Feb 5;6:10699-707.

[31] Semerádová T, Weinlich P. The (In) Effectiveness of In-Stream Video Ads: Comparison of Facebook and YouTube. InResearch Anthology on Strategies for Using Social Media as a Service and Tool in Business 2021 (pp. 668-687). IGI Global.

[32] Lawler III EE, Benson GS. The practitioner-academic gap: A view from the middle. Human Resource Management Review. 2020 Jun 19:100748. 